\title{
Enhancing The Quality Of Teaching And Learning Through Action Research
}

\author{
Sepideh Mahani, Higher Colleges of Technology, United Arab Emirates
}

Arman Molki, The Petroleum Institute, United Arab Emirates

\begin{abstract}
In every society, a great deal is expected from teachers. They are often expected to react sufficiently and proactively to the ongoing changes in the world and amend their instructional methods and resources to help students reach their academics potential. In today's society, teachers are persistently in pursuit of developing ways to reach the new generation of students who are perhaps the most globalized and tech-savvy to date. While academic researchers continue to investigate and analyze current educational issues and trends, the products of these studies have limited practicality to classroom teachers. As a result, teachers are encouraged to collaborate with their colleagues and engage in action research in order to tackle issues specific to their classroom practices and teaching. Some examples of action research in educational settings include educators who wish to undertake research in their classrooms or schools for the purpose of improving teaching, to test educational theory, or to evaluate and implement an educational plan. In this paper, the authors will analyze action research as a method of intellectual inquiry in education settings. Furthermore, they will examine the common methodologies, data collection and analysis in action research and will illustrate the advantages and disadvantages of action research.
\end{abstract}

Keywords: Action Research; Teaching; Learning; Research Methodology

\section{INTRODUCTION}

(๑)

ver the years, action research has become a term that is often discussed among practitioners in educational settings. McNiff and Whitehead (2010) defined action research as a method of research and inquiry, practiced mostly by educators and practitioners in educational institutions. This type of research is different from other methods of research because it is a contemplative process that encourages analysis and debates as the foundation of the research practice. The objective of conventional social and scientific research is to recognize and define a social condition in order to create a deeper understanding of the situation; hence, improving the individual's behavior in this situation. However, action research does not focus on improving behavior, but its' main goal is to improve learning (McNiff \& Whitehead, 2010). Educators engage in action research in the classroom in order to assess their own teaching with regard to student learning. Action research is most often a cooperative endeavor between educators that work in the same educational setting and those who are in pursuit of finding a resolution or clarification to a difficulty on hand. Educators that engage in action research often seek to uncover a way to improve a certain activity; hence, instead of focusing on theory, researchers emphasize on issues that are directly relevant to them and their educational environment (Ozanne \& Saatcioglu, 2008). Throughout the process, educators who engage in action research, assess the issue on hand, record the various stages of the examination, analyze the data gathered, and finally create a new awareness about the issue and make relevant decision that proceeds to improvement of the situation. Consequently, educators engage in action research to bring about a change, improve an existing problem, or enhance a routine practice (Ozanne \& Saatcioglu, 2008; Young, Rapp \& Murphy, 2010). 


\section{ACTION RESEARCH}

According to McNiff and Whitehead (2010), action research can be described as a process of finding different methods and approaches to enhance a practice; thus, action research is about creating awareness and understanding, in order to improve a certain practice, and often exhibits an educational objective. Consequently, researchers who carry out action research do so in pursuit of a creating new knowledge that did not exist before. McNiff and Whitehead (2010) add that action research is not only about professional practice, but its' main purpose is to improve a certain existing practice while creating new knowledge. Since action research is deliberately political, its' goal is to generate a set of new knowledge that will contribute to the society. Furthermore, action research concentrates on enhancing learning and not enhancing behavior of the subject. It is often carried out through collaborative work and contains questioning, examination and deconstruction of existing knowledge. Young et al. (2010) defined action research as an applied academic theory resulting in action for a particular setting; hence, offering educators innovative approaches for improving their teaching and student learning. The feature that sets action research apart from other research methods is that in action research, the researcher approaches the question analytically. Thus, action research does not test a hypothesis in search of a generalized answer, but it seeks a methodical consideration with a focus on teaching and learning (Choudry, 2010; Ozanne \& Saatcioglu, 2008; Young et al., 2010). Zuber-Skerritt and Fletcher (2007) created the CRASP model, which is a theoretical structure that was influenced by the Frankfurt School of Critical Theory for action research. The CRASP model represents the five elements of theoretical structure and includes Critical, Reflective, Accountable, Self-evaluating and Participative. Through critical inquiry and collaborative work, educators reflect on their practices and issues on hand and are accountable for the results of their inquiry; hence, through the process of self-evaluation and their practices, they begin a participative problem-solving phase in order to improve their practices.

\section{Origins of Action Research}

Educational action research was created in the 1940s through the works of Kurt Lewin and John Collier. Between 1933 and 1945, Collier served as a Commissioner of Indian Affairs and is often perceived as one of the first founders of action research. He dedicated most of his research to creating community, in connection to educational and social framework among Native Americans (McNiff \& Whitehead, 2010). Kurt Lewin, an American psychologist and an educator, first introduced that research can be conducted in a natural environment in order to modify the approach or the manner in which researchers interact within their environment (Newton \& Burgess, 2008; McNiff \& Whitehead, 2010). Lewin's research was often directly associated with the issues he encountered. His research process was conducted in a recurrent cycle which involved planning, investigating, observing, reflecting, and finally applying the changes from the results he gathered, in order to modify or improve the situation (McNiff \& Whitehead, 2010). Furthermore, Collier was an advocate of social, economic, and political impartiality in both schools and higher educational institutions. He believed action research was a participatory research method where the researcher identifies a problem and engages in the research framework. Collier's model has been influential in shaping action research; however, Lewin is considered the principal founder of action research because he established the analytical approaches in action research that is immensely practiced today (Newton \& Burgess, 2008; McNiff \& Whitehead, 2010).

From the mid-1950s to 1960 's, action research was criticized for being unscientific. It was also condemned due to its connection to political activism (Stringer, 2007). However, in the 1970s, action research reemerged among educational practitioners who perceived it as the most appropriate method for solving the problems they faced on a daily basis in their educational settings (Newton \& Burgess, 2008; McNiff \& Whitehead, 2010). Today, action research is an instrument for educators who are in pursuit of improving their educational practices and developing their profession. Action research continues to develop as a research method and, since its foundation in the 1940s, it has developed significantly. Some of the developments in action research have been linked to Progressive Education movement, specifically to the ideas of scholars such as John Dewy, Hilda Taba and Stephen Corey (Newton \& Burgess, 2008). Stephen Corey, an educator at Teachers College at Colombia University, believed that action research was the most appropriate method of research for educators in an educational setting because educators would concurrently be involved in research and application of knowledge in their setting. Furthermore, he believed that action research is an effective method of inquiry because it focuses on the issues on hand rather than 
being a generalization that could affect different fields or settings (Newton \& Burgess, 2008; McNiff \& Whitehead, 2010).

\section{ACTION RESEARCH METHODOLOGIES}

Grundy (1988) stated that there are three different types of action research - technical, practical and emancipatory. In the technical type of action research, the researcher's goal is to test a specific intrusion through a predetermined theoretical structure. The researcher's objective is to draw the practitioner's attention to the research and, through collaboration and involvement of the practitioner, help utilize the newly gathered knowledge and resolution (French, 2009; Grundy, 1988). The practical type of action research necessitates the collaboration of the researcher and practitioners. It is through this involvement and collaboration that the research problem is identified, data are gathered and analyzed, and a solution is reached. In this process, the researcher urges the practitioner to be fully involved in order for the practitioner to benefit from the self-transformation and empowerment (French, 2009; Grundy, 1988).The emancipatory type of action research demands that all the participants should be involved in the research equally and there should not be a chain of command between the researcher and all the participants. Hence, the researcher's objective is to decrease the gap between the research problem and the theory used to describe and solve the problem. The researcher engages in dialogs with all the participants in order to identify the fundamental problems in the situation. In this type of action research, the researcher is a member of the research group which involves all the participants; hence, the intention of emancipatory action research is to emancipate and empower the participants through involvement and limit the practice of coercion and dictation (French, 2009; Grundy, 1988).

Action research is conducted through series of cyclical or spiral stages. There are four steps involved in the action research spiral, which include developing a plan, acting on and implementing the plan, observing the action, and reflecting on the data gathered. If the desirable outcome is not reached, the researcher is then encouraged to replan, re-collect and reflect. Allowing the researcher to go backward and forward throughout the cyclical process demonstrates that some stages of the research can be repeated until a desirable solution is reached (French, 2009; Grundy, 1988).

\section{Identifying the Problem}

The first step in conducting an action research is to identify a plan. In this stage, the researcher identifies the problem and acknowledges that a change of action is required (French, 2009; Grundy, 1988). The researcher then forms a group and ensures that the participants approve and agree with the concerned problem and have a desire to pursue a solution and improve the situation. The second step of action research is acting and implementing the plan, which is when the group members and the researcher employ the plan. The third step is observation and, in this stage, the researcher begins to collect data through evaluation and observation. Finally, the fourth stage is the reflection stage, where the researcher begins data analysis (French, 2009; Grundy, 1988).

\section{Data Collection}

In the conventional methods of research, there are particular methods of data collection that a researcher can use while collecting data; however, in action research, there is not one particular method of data collection that the researcher must follow. Educators conducting action research often gather data through observation, interviews, audio, and video recording, or keeping a journal. It is essential that researchers collect and record their data and archive them systematically in order to be able to retrieve and identify them in the next stages of the research process (French, 2009; Grundy, 1988; McNiff \& Whitehead, 2010).

\section{Data Analysis}

Data analysis in action research occurs during the reflective stage of the action research process. The purpose of this stage is to offer the researcher the essential awareness required in order for the research to move forward. While the researcher is the only interpreter of the data, Gundy (1988) suggested that it is important for the researcher to seek other's understanding and analysis of the data through consultations or through dialogues with the participants in the research. The term triangulation has been given to this process of cross referencing between the 
participants and the researcher, and it is perceived as an important step in the data analysis process because it provides a better perception of the issue and also enlightens and empowers the participants (French, 2009; Grundy, 1988).

\section{Advantages of Action Research in Higher Education}

One of the most important principles that makes action research beneficial to communities and favorable to researchers is its attentiveness to human condition and its attention to solving community-based problems. Stringer (2007) stated that the goal of action research is to help solve complexities that people in different groups or communities face, thus helping them solve their problem and understand their situation better. Consequently, of all the research methods, action research is the most attentive to community and social issues. Stringer (2007) believes that action research is a constructive method of research since it is democratic and allows people to participate in the research process and promotes equality among individuals. Furthermore, action research is liberating since it offers humans, independence and autonomy from harsh situations and empowers them by allowing them to express their voice (Stringer, 2007).

Among educators, educational action research is perceived as a tool that advances and encourages them to be effective and analytical facilitators. Through action research, educators are empowered to question and challenge traditional guidelines and methods of instruction, which enables them to take authoritative steps toward evolving their professional abilities. In every occupation, professional development refers to enhancing ones knowledge of the field, growing in that specific arena and progressing through a professional cycle that possibly leads to a superior status, better benefits, and greater power. In an educational context, however, teacher development manifests pedagogical, social, and historical changes in the society; hence, educators work toward creating enhanced methods and strategies to transform their skills (Choudry, 2010; Fandino, 2010).

Fandino (2010) argues that professional development in teaching is not merely about demanding transformations to meet the society's educational needs or tackling the problems within the educational system, but professional development among teachers means taking authoritative steps toward changing their own lives and their professional capabilities. Therefore, by examining their own lives, circumstances and practices, teachers enter a dialogue with themselves which results in encouragement, inquiry, and self-discovery. Therefore, this practice creates teachers who are active knowers and are responsible for enhancing their professional skills, as well as making them critical agents who are able to use acquired understanding to change their practices (Fandino, 2010; Odhiambo, 2010). In an educational context, action research is beneficial since it acts as a tool that develops and empowers teachers. Fandino (2010) argues that teacher empowerment is essential to the profession because it provides them the ability to express their opinions in educational matters, resulting in a sense of significance in the decision-making process, hence providing them with a sense of accountability for their own growth. According to Fandino (2010), there are six elements in teacher empowerment - professional development, autonomy, involvement, teacher impact, teacher status, and teacher self-efficacy. Through these six elements, the teacher feels empowered because the educational setting for which they work provides them with opportunities where they can develop their skills, and it gives them a sense of self-assurance and autonomy by allowing them to participate in the decision-making process. Therefore, action research is a beneficial instrument that helps empower educators by encouraging them to build and enhance their pedagogical practices and provides them with an influential voice to impact decisions regarding their educational setting.

\section{Disadvantages of Action Research in Higher Education}

Nolen and Putten (2007) argue that one of the criticisms of action research is often focused on ethical issues. Since action research relies heavily on involvement of various participants, such as teachers, administrators, parents, students, and members of the community, the ethical issue that often arises is that some of the roles in the study clearly conflict with one another. While action research projects have provided society and their communities with valuable knowledge and information, it is important to note that ethical issues that often arise in action research projects are complex and do not exist in conventional research methods. Critiques of action research question the boundaries of the research and speculate how the researcher or teacher withdraws the research from their teaching. Critics also question whether the teachers, who are involved in action research, have been accurately trained and are 
aware of the ethical consequences of research, especially since teachers use students - who are minors - as participants in their research. The absence of ethical protocol could result in ethical dilemmas, especially since students in a K-12 system are minors and might not be aware of their rights. For example, if these students were asked to partake in a study, they will most likely agree due to their lack of maturity and independence, especially if the request is coming from an authoritative person such as a teacher (Nolen \& Putten, 2007).

In action research projects where there is a collaboration between a school, teachers and a higher education institution, the university's IRB requires that the researcher follow the university's ethical regulations while conducting a research. Hence, a formal contract is created, consent forms are reviewed and approved, and everyone involved in the project is made aware of the ethical consequences. In case ethical issues arise during the project, the university's IRB will address the issue (Nolen \& Putten, 2007). However, in action research projects where there is no collaboration between the school and a university, the researcher, who may be a principle, teacher, librarian or a counselor, will act as the sole researcher; hence, there will more likely be a conflict of interest since the researcher is satisfying two roles and could hinder the research process, student's learning, and the classroom dynamics (Nolen \& Putten, 2007). Another critique of educational action research is the distance that it creates between the educators and students. Newton \& Burgess (2008) suggested that teachers involved in action research are not able to perform their educational responsibilities sufficiently since they are so involved in their research. Teachers involved in action research favor to spend their time on the research since it attends to the issues they are dealing with; hence, they prefer to engage in the research and find a solution to the problem and unconsciously tend to prioritize the research to their other tasks. Another criticism of educational action research suggests that since the teacher, as researcher, is directly involved in the problem and the situation, how could the researcher offer an unbiased reflection (Newton \& Burgess, 2008).

\section{Action Research and the Community}

Higher education institutions have always existed to serve the members of society by creating and transforming knowledge. They are often the essence of cultural, social and political transformation and revolutions. Higher education institutions have always been perceived as a place where knowledge originates. However, Weber (2011) argues that higher education institutions are not the only place from where knowledge originates, but very often, new ideas and social movements originate from communities in the society. Ideas, such as women's studies, instigated from political movements and communities. In the 1960s and 70s, a popular mantra started within the women's movement, which states that personal was political. Today, concepts, such as motherhood and marriage, are being reconstructed and given a new sociological meaning as a result of collaborative work between feminist groups and higher education institutions. Therefore, action research in higher education institutions should not be perceived merely as research or academic projects, but as origins of political and social reform (Weber, 2011; Zuber-Skerritt \& Fletcher, 2007).

Weber (2011) indicated that action research has been an important bridge between university and community collaboration, outreach programs, and service-learning initiatives in the United States. For example, there have been numerous action research projects in the United States through collaborative work between higher education institutions and communities. One of the projects examined interpersonal associations between different electorates with the purpose of improving the partnership between the university and campus community. Another study recommended a collaborative model between universities, government agencies, and campus communities, which involved introduction, negotiation, and application of new recommendations (Weber, 2011). Consequently, higher education institutions can use action research and collaborative work with the government and their community to challenge socio-economic problems in their community and bring about social justice and transformation in their society. Therefore, in higher education institutions, action research agendas should focus on the problems that exist within the society and their immediate communities, and through collaborative work between the institutions and the communities, and involving participants from the community, higher education institutions can, in fact, become major players in not only defining the problems, but also uncovering the solutions. 


\section{CONCLUSION}

In the American education system today, many topics, such as equality, access, and students success, are being analyzed and researched. While academic researchers continue to investigate these issues, the products of these studies have limited practicality to classroom teachers. Therefore, for teachers to identify immediate and practical solutions to the issues they face in classrooms, they are encouraged to engage in action research in order to tackle and solve these issues through collaboration with their colleagues. In conclusion, action research is distinctive from other methods of research since it integrates research with action. It is conducted through collaborative work between the researcher and the participants; it involves high levels of sensitivity toward its participants; it creates new knowledge that produces powerful and life changing results for the participants; and, most importantly, it creates social and political transformation and social justice (Somekh, 2006).

\section{AUTHOR INFORMATION}

Sepideh Mahani is a Liberal Arts and Communications lecturer at the Higher Colleges of Technology in Abu Dhabi, United Arab Emirates. She graduated with a Bachelors degree in Political Science from York University, Canada, a TEFL diploma from the University of Saskatchewan and a Master of Education in Higher Education Leadership from Northcentral University. She is currently a doctoral candidate in the School of Education at the Northcentral University in the United States. Her research interests include minority students, first-generation students, globalization of higher education, andragogy and the role of post-secondary institutions and higher education policy in facilitating access for and the success of women in STEM fields. Presently she is leading the development of an Ethical Studies course for EFL learners at Higher Colleges of Technology. She is a member of Association for the Study of Higher Education (ASHE) and Kappa Delta Pi, international honour society. E-mail: smahani@hct.ac.ae. Corresponding author.

Arman Molki is a Senior Engineer in the Department of Mechanical Engineering at the Petroleum Institute, Abu Dhabi, UAE. His research interests include education technology, engineering education, sensors and instrumentation, and data acquisition systems. He has undergraduate and graduate degrees from the University of Maryland, College Park and Northcentral University respectively. Mr. Molki is presently pursuing a $\mathrm{PhD}$ degree in education technology from Northcentral University. He is a member of the American Society of Mechanical Engineers (ASME), International Society for Technology in Education (ISTE), Kappa Delta Pi, and Delta Mu Delta. E-mail: amolki@pi.ac.ae

\section{REFERENCES}

1. Choudry, A. (2010). Education, participatory action research, and social change: International perspectives. International Education, 39(2), 72-72-76. Retrieved from http://search.proquest.com/docview/744216744? accountid=28180

2. Fandino, Y. J. (2010). Research as a means of empowering teachers in the 21 st century. Educacion $y$ Educadores, 13(1), 109-109-124. Retrieved from http://search.proquest.com/docview/722536263? accountid=28180

3. French, S. (2009). Action research for practising managers. The Journal of Management Development, 28(3), 187-187-204. doi: 10.1108/02621710910939596.

4. Grundy, S. (1988). Three modes of action research. In S. Kemmis(Ed.), The action research reader ( $3^{\text {rd }}$ ed, pp. 353-364). Victoria, Australia: Deakin University Press.

5. McNiff, J., \& Whitehead, J. (2010). You and your action research project (third edition). London: Routledge.

6. Newton, P., Burgess, D. (2008). Exploring types of educational action research: Implications for research validity. International Journal of Qualitative Methods, 7(4), 18-30. Retrieved from EBSCO host.

7. Nolen, A. L., \& Putten, J. V. (2007). Action research in education: Addressing gaps in ethical principles and practices. Educational Researcher, 36(7), 401-407. Retrieved from http://search.proquest.com/docview/216900972?accountid=28180 
8. Odhiambo, E. (2010). Classroom research: A tool for preparing pre-service teachers to become reflective practitioners. Journal of Instructional Pedagogies, 4(1), 1-14. Retrieved from http://search.proquest.com/docview/759652448? accountid=28180

9. Ozanne, J. L. \& Saatcioglu, B. (2008). Participatory Action Research. Journal of Consumer Research, 35(8), 423-439. Retrieved from EBSCO host.

10. Somekh, B. (2006). Action research: A methodology for change and development. Maidenhead, Open University Press.

11. Stringer, E. T. (2007). Action Research: A handbook for practitioners 3 e, Newbury Park, CA: Sage.

12. Weber, E. E. (2011). Transforming higher education: Action research, learning and community politics. Africa Education Review, 8(1), 1-16. doi: 10.1080/18146627.2011.286138.

13. Young, M. R., Rapp, E., \& Murphy, J. W. (2010). Action research: Enhancing classroom practice and fulfilling educational responsibilities. Journal of Instructional Pedagogies, 3(1), 1-10. Retrieved from http://search.proquest.com/docview/759646028?accountid=28180

14. Zuber-Skerrit, O., \& Fletcher, M. (2007). The quality of an action research thesis in the social sciences. Quality Assurance in Education, 15(4), 413-436. doi: 10.1108/09684880710829983. 
NOTES 